\section{Intra-lesional 5 fluorouracil for the management of recurrent pterygium}

DG Said ${ }^{1,2,4}$, LA Faraj ${ }^{1,4}$, MS Elalfy ${ }^{1,2}$, A Yeung ${ }^{1}$, A Miri ${ }^{1}$, U Fares ${ }^{1}$, AM Otri ${ }^{1}$, I Rahman ${ }^{1,3}$, S Maharajan ${ }^{1}$ and HS Dua ${ }^{1}$

\begin{abstract}
Aim Recurrence is the most common complication arising from pterygium surgery. The aim of this study was to investigate the effectiveness of 5 fluorouracil (5FU) in halting the recurrence of pterygium after surgical excision.

Methods A retrospective review of patients treated for pterygium recurrence was carried out. Patients with recurrent (secondary) pterygium were treated with multiple weekly intra-lesional injections of 0.1-0.2 ml (2.5-5 mg) 5FU post-operatively depending on the size of the recurrence. The treatment was started within 1 month from the date of recurrence. The time from surgery to start of recurrence, previous treatment modalities, and number of recurrences were documented. The number of injections required to induce arrest of progression and/ or regression of vascularity and fleshiness of the pterygium and any complications related to 5FU treatment were examined.

Results Fifteen eyes from 14 patients with recurrent pterygium treated with intralesional 5FU injections were analysed. Three of the $\mathbf{1 5}$ eyes had undergone a secondary excision and $\mathbf{1 2}$ had undergone a primary excision. In all, $93.3 \%$ of patients showed regression of the fibrovascular tissue (thickness and vascularity) and arrest of progression following a dose of $0.1-0.2 \mathrm{ml}$ (2.5-5 mg) 5FU. Twelve eyes required three injections or fewer, whereas one patient required eight injections. This beneficial effect was maintained over an average follow-up period of 17 months. No complications from 5FU were observed. Conclusion The use of weekly intra-lesional $5 \mathrm{FU}$ injections for the treatment of recurrent pterygium is safe and effective in limiting the progression and inducing the regression
\end{abstract}

of recurrent pterygium. The number of injections can be tailored according to clinical need.

Eye (2013) 27, 1123-1129; doi:10.1038/eye.2013.135; published online 28 June 2013

Keywords: recurrent pterygium; 5 fluorouracil; antimetabolite; conjunctival recurrence

\section{Introduction}

Pterygium is a fibrovascular growth, primarily consisting of elastotic degeneration of the subconjunctival tissue, presenting as a wing-shaped lesion extending on to the cornea. The indications for surgical excision include progression threatening the visual axis, induced astigmatism, restriction of eye movement, chronic irritation, and poor cosmesis.

The gold standard treatment is surgical excision of the pterygium with an autologous conjunctival graft, which is either stitched or glued with fibrin glue to cover the defect. ${ }^{1}$

Other options such as excision with bare sclera, primary closure of the defect, and amniotic membrane grafting have also been reported. ${ }^{2}$ Recurrence rates of pterygium range from 10 to $>80 \%$ depending on the excision procedure; for the bare sclera technique it is at the higher end, reaching up to $82 \%$ in some studies, ${ }^{2-4}$ and hence this approach has been abandoned by many surgeons. Excision with autologous conjunctival transplant is at the lower end of the range.,6 More recent studies suggest an overall recurrence rate of $18 \%$ after pterygium surgery. ${ }^{7}$ Other risk factors for recurrence include young age, dark race, incomplete removal, and fleshy nature of the pterygium. ${ }^{2}$

Several adjunctive treatments have been employed to reduce recurrences. These include

\begin{abstract}
${ }^{1}$ Department of Ophthalmology, Nottingham University Hospitals, University of Nottingham, Nottingham, UK
\end{abstract}

${ }^{2}$ Cornea and Ocular Surface Unit, Research Institute of Ophthalmology, Cairo, Egypt

${ }^{3}$ Department of Ophthalmology, Blackpool Victoria Hospital, Blackpool, UK

Correspondence: HS Dua, Department of Ophthalmology, Queen's Medical centre, Floor B, Research Room, Derby Road, Nottingham NG7 2UH, UK.

Tel: + 44 (0)1159249924 ext 62537;

Fax: + 44 (0)115970996. E-mail: harminder.dua@ nottingham.ac.uk

Previous presentations of the work: Oral presentation at EuCornea2012, Milan. Oral presentation, Cardiff 2010.

${ }^{4}$ Dalia Said and Lana Faraj are joint first authors.

Received: 15 November 2012

Accepted in revised form: 17 May 2013 Published online: 28 June 2013 
steroids to reduce inflammation and scarring, ${ }^{8}$ peri-operative application of antimetabolites such as mitomycin C $(\mathrm{MMC})^{9}$ or 5 fluorouracil (5FU), ${ }^{10,11}$ and, more recently, the use of anti-VEGF antibodies administered topically or subconjunctivally. ${ }^{12,13}$

Other previously adopted techniques such as beta radiation have been abandoned because of the high risk for scleral melt. ${ }^{14}$

$5 \mathrm{FU}$ is a pyrimidine analogue that interferes with DNA and RNA synthesis. ${ }^{15,16}$ 5FU induces apoptosis of the Tenon's fibroblasts and has anti-proliferative fibroblastic properties. ${ }^{17,18}$ In ophthalmology, 5FU is widely used because of its anti-scarring properties. In 2007, we reported a single case of multiple post-surgical recurrences of pterygium in an Afro-Caribbean lady who was successfully treated with intra-lesional (5FU) injection following the fourth operation. ${ }^{19}$ The effective role of 5FU in halting pterygium recurrence has been discussed by others as well. ${ }^{10,11}$ We have now adopted intra-lesional 5FU injection as a routine in the management of recurrent pterygium and report our results herein.

\section{Material and methods}

All patients with signs of early recurrence of pterygia from October 2006 to June 2011 were included in this study. Demographic data, time from surgery to recurrence, number of recurrences, and previous treatment modalities were documented. Case note entries as well as photographic images were used to assess recurrence and improvement after injections.

Criteria for start of treatment included the following:

1. Increased vascularity of the conjunctiva at the site of original excision showing tortuous and active vessels associated with thickening of the conjunctiva appearing after the initial redness and swelling related to surgery had settled.

2. Clinically documented progression of fibrovascular tissue over two or more follow-up visits, which did not settle with increased doses of topical steroids with or without frank encroachment on to the cornea.

Reperfusion injury of the grafted conjunctiva manifesting as diffuse injection and swelling, occasionally with haemorrhages resolved by 4 weeks. Localised re-appearance of fibrovascular tissue with injected vessels and thickening of tissue thereafter was taken as conjunctival recurrence of pterygium.

Success was defined as arrest of progression and/or regression of vascularity and thickness of the conjunctiva at the site of the lesion. Images from our previously published case, both before and after injections, were used as reference pictures to determine the beneficial effect of the injections. ${ }^{19}$ The arrest of progression was considered when no further advance of the lesion was noted over three follow-up visits, 1-2 weeks apart.

\section{Surgery}

The head of the pterygium was dissected off the cornea and the neck lifted off the limbus. The head and neck were excised. The fibrovascular tissue (including affected Tenon's capsule) was separated from the overlying conjunctiva and dissected medially up to the caruncle and superiorly and inferiorly until normal Tenon's was visible. All the fibrovascular tissue thus dissected was excised. The conserved conjunctiva was placed back over the defect and the remaining area of the defect was measured with surgical calipers. The donor site for autologous conjunctiva was marked to correspond to the size of the defect and harvested without taking any underlying Tenon's capsule.

We treated 15 eyes from 14 patients by injecting $0.1-0.2 \mathrm{ml}$ of $5 \mathrm{FU}(2.5-5 \mathrm{mg})$ into the body of the recurring pterygia. The 5FU solution was prepared locally in our pharmacy for ophthalmic use. It was delivered preloaded in a $1-\mathrm{ml}$ syringe containing $0.3 \mathrm{ml}$ of $25 \mathrm{mg} 5 \mathrm{FU}$ per $1 \mathrm{ml}$. The injection was given under topical anaesthesia (tetracaine hydrochloride $1.0 \% \mathrm{w} / \mathrm{v}$, Bausch \& Lomb UK Ltd, Kingston-upon-Thames, UK). One to two drops of $5 \%$ povidone iodine (Moorefield's Pharmaceuticals, London, UK) were instilled in the conjunctival sac $5 \mathrm{~min}$ before the injection. All injections were given in the outpatient clinic using a slit lamp. The needle (27 Gauge) was advanced in a zigzag manner into the subconjunctival space, avoiding any large blood vessels, until the middle of the lesion was reached. The solution was then injected and the needle withdrawn. After the injection, 1-2 drops of chloramphenicol $0.5 \%$ preservative-free minims were instilled topically (Bausch and Lomb/Chauvin) and continued four times a day for 3 days after each injection. Injections were carried out at weekly intervals (except in the case of two patients in whom an injection was delayed to 2 weeks because of problems with the 5FU preparations from the local pharmacy) until the progression had halted and the pterygium had become inactive.

Signs of inactivity included reduced injection as determined by decrease in vessel engorgement, flattening of the lesion, and arrest of progression on subsequent follow-up visits as described above.

All patients also received topical prednisolone acetate $0.5 \%$ four times per day between injections and for 
1-2 months thereafter to combat any inflammation induced by the trauma of the injection.

Approval for the retrospective review of case notes was obtained from the Queens Medical Centre, Nottingham, UK (approval number 1758).

We certify that all applicable institutional and governmental regulations concerning the ethical use of human volunteers were followed during this research.

\section{Results}

Fifteen eyes from 14 patients (six women and eight men) were treated. The mean age was 41.9 years (range: $27-74$ ). Of the 15 eyes, 12 had undergone primary excision of the pterygium and three had undergone more than one surgical procedure for pterygium previously. Clinical details of patients and previous pterygium removal, details of the latest pterygium removal, and treatment of recurrence with 5FU are given in Table 1.

All patients had undergone standard excision of the pterygium with closure of the defect using an autologous conjunctival graft taken from the superior bulbar conjunctiva. In eight eyes the autologous conjunctival graft was sutured in place and in seven eyes it was glued with fibrin glue (Tisseel Lyo, Baxter Healthcare Ltd, Thetford, UK). Eight eyes had received adjuvant intra-operative MMC $0.04 \%$ application (five with sutured grafts and three with glued grafts) for 3-5 min under the conjunctiva at the edge of the excised tissue, followed by copious irrigation with balanced salt solution.

The mean time to recurrence was 4.5 months (range: 39 days-13.6 months) from the preceding surgical excision. The average period of start of treatment after detection of recurrence was 7.5 days (range 0-26 days) and the mean number of injections required for treating the recurrence was 3.3 (range: $1-8$ ). The mean follow-up period was 17.2 months (range: 6.5-44 months).

The clinical appearance improved in $93.3 \%$ (14 out of 15) of treated eyes as seen by decreased vascularity, regression of conjunctival thickening, and arrest of progression (Figure 1). It was also noted that early recurrence manifested as a localised area of thickening and vascularisation on the conjunctiva (conjunctival recurrence, Figure 2d) at the site of the original surgery. One patient developed post-operative steroid-induced raised intraocular pressure, which resolved on discontinuation of the drops. No complications from $5 \mathrm{FU}$ were noted in any patient. Six patients developed subconjunctival haemorrhage during injection, which resolved spontaneously within 2 weeks. Importantly, we did not see any punctate keratitis or manifest epithelial defects.

\section{Discussion}

Pterygium is an active process that involves inflammation, cellular proliferation, migration, and vascularisation. ${ }^{20}$ Recurrence is the single most important complication following surgical excision of the pterygium. The recurrence risk rises with increasing number of excisions. In their 12-month follow-up study, Tan et $a l^{2}$ stated that $92 \%$ of recurrences occurred within the first 6 months following surgical excision; however, recurrence has been reported years after surgery and we observed two cases in which it recurred more than 1 year after surgery. It is now commonly accepted that pterygium excision with an adjuvant auto-conjunctival graft has a lower recurrence rate compared with excision

Table 1 Patient demographics, surgery, 5FU injection, and follow-up data

\begin{tabular}{|c|c|c|c|c|c|c|c|c|c|c|c|}
\hline $\begin{array}{l}\text { Patient } \\
\text { number }\end{array}$ & $\begin{array}{c}\text { Age } \\
\text { (years) }\end{array}$ & Sex & $\begin{array}{l}\text { Eye } \\
\text { treated }\end{array}$ & $\begin{array}{l}\text { Pterygium } \\
\text { type }\end{array}$ & $\begin{array}{l}\text { Adjunctive } \\
\text { MMC } \\
0.04 \%\end{array}$ & $\begin{array}{l}\text { Auto- } \\
\text { conjunctival } \\
\text { closure }\end{array}$ & $\begin{array}{c}\text { Time to } \\
\text { recurrence } \\
\text { following last } \\
\text { excision (days) }\end{array}$ & $\begin{array}{c}\text { Number of days } \\
\text { to start of } 5 F U \\
\text { injection }\end{array}$ & $\begin{array}{c}\text { Total } \\
\text { number of } \\
\text { injections }\end{array}$ & $\begin{array}{l}\text { Follow-up } \\
\text { time } \\
\text { (months) }\end{array}$ & $\begin{array}{c}\text { Further } \\
\text { progression }\end{array}$ \\
\hline 1 & 46 & Male & Right & Secondary & NA & Suture & 42 & 26 & 2 & 21.10 & No \\
\hline \multirow[t]{2}{*}{2} & 45 & Male & Right & Primary & NA & Suture & 55 & 7 & 3 & 9.97 & No \\
\hline & & & Left & Primary & NA & Suture & 412 & 7 & 8 & 6.63 & No \\
\hline 3 & 74 & Male & Right & Primary & Applied & Suture & 39 & 0 & 3 & 9.73 & No \\
\hline 5 & 32 & Male & Right & Primary & Applied & Glue & 408 & 5 & 3 & 24.53 & No \\
\hline 6 & 43 & Male & Right & Primary & Applied & Suture & 262 & 7 & 4 & 13.57 & No \\
\hline 7 & 30 & Female & Right & Primary & NA & Suture & 90 & 0 & 3 & 32.87 & No \\
\hline 8 & 28 & Male & Right & Primary & NA & Glue & 76 & 2 & 5 & 8.13 & No \\
\hline 9 & 27 & Female & Right & Primary & Applied & Glue & 117 & 1 & 3 & 6.53 & No \\
\hline 10 & 31 & Male & Right & Primary & Applied & Glue & 58 & 14 & 3 & 21.70 & Yes \\
\hline 11 & 59 & Male & Right & Primary & Applied & Glue & 149 & 7 & 1 & 8.33 & No \\
\hline 12 & 35 & Female & Right & Secondary & Applied & Glue & 69 & 9 & 3 & 18.63 & No \\
\hline 13 & 36 & Female & Right & Primary & NA & Glue & 99 & 5 & 3 & 15.20 & No \\
\hline
\end{tabular}

Abbreviations: MMC, mitomycin C; NA, not applied; 5FU, 5 fluorouracil. 


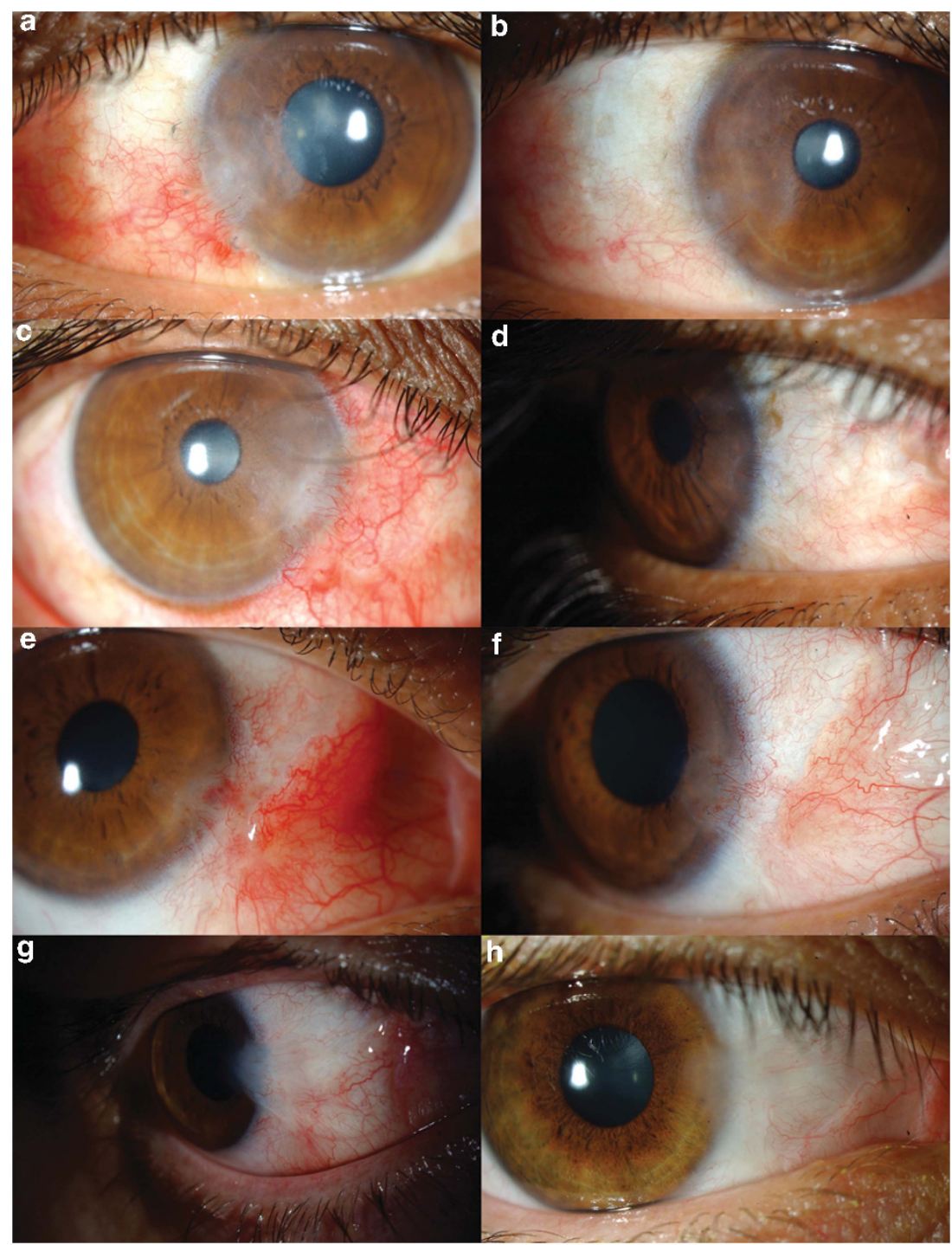

Figure 1 Slit-lamp diffuse images: left column represents pre-injection images of recurrent pterygium and the right column represents the post-injection resolution of the recurrence. (a) (Patient no. 2, left eye) Showing predominant conjunctival recurrence and early corneal recurrence 412 days after primary excision without MMC. (b) (Patient no. 2, left eye) Showing resolution after 8 injections of 5FU. (c) (Patients no. 2 right eye) Showing recurrence of pterygium 55 days after primary excision without MMC. (d) (Patient no. 2, right eye) Image showing resolution after three injections of 5FU. (e) (Patient no. 6) Showing predominant conjunctival recurrence with early corneal recurrence 262 days after primary excision with MMC. (f) (Patient no. 6) Shows resolution of vascularisation and thickness after four injections of 5FU. (g) (Patient no. 12) Showing recurrence of pterygium 69 days after excision of secondary pterygium with MMC. (h) (Patient no. 12) Shows resolution of vascularisation and thickness after three injections of 5FU.

with direct closure or amniotic membrane transplantation. ${ }^{2,3,5,21}$ There is an increasing tendency to use fibrin glue rather than sutures to attach the autologous conjunctival graft. There is some evidence that the use of fibrin glue instead of sutures to anchor the conjunctival graft may be associated with a lower recurrence rate, besides other advantages such as reduced surgical time and increased patient comfort. ${ }^{22,23}$ This could be due to reduction in inflammation from the stitches used to fix the graft in place. In one patient in whom we used a 10/0 nylon suture to fix the graft, recurrence was noted at the edge of the suture knot.

In our study, recurrence related to both sutures and gluing responded to 5FU injection similarly.

Another problem with repeated surgery is that it can lead to extensive scarring of the conjunctiva, and obtaining autologous conjunctiva for grafting becomes increasingly difficult. The use of intra-operative antimetabolites, such as MMC, is well established in clinical practice, especially in high-risk cases such as 


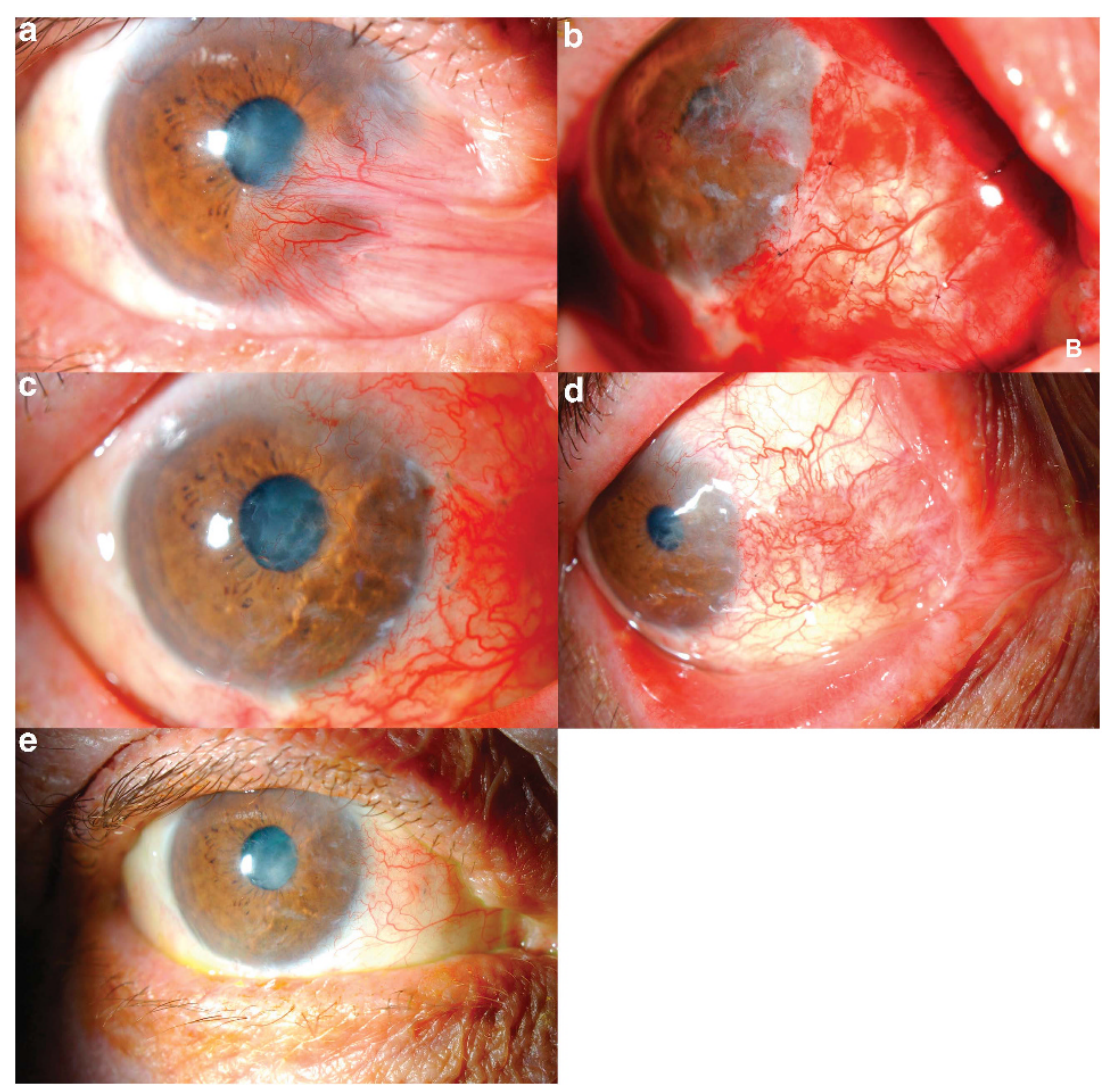

Figure 2 Slit-lamp diffuse images: these images are of patient no. 3. (a) Thick fleshy primary pterygium just before excision with autoconjunctival grafting and MMC intra-operative application. (b) The appearance of the graft and the reperfusion injury on the fourth post-operative day. (c) Graft diffuse injection and swelling settling down 3 weeks post-operatively. Areas of graft haemorrhage are no more seen. (d) Conjuctival recurrence of the pterygium 39 days post-operatively. (e) The appearance after regression of the recurrent pterygium.

patients who had experienced previous recurrence, patients belonging to the Afro-Caribbean or Asian race, and patients with a tendency for keloid formation. ${ }^{24}$ Although intra- and post-operative use of $5 \mathrm{FU}$ has been discussed previously in isolated reports, few studies have attempted to show the beneficial use of intralesional 5FU injections for early recurrences. ${ }^{10,11,25}$

As demonstrated in this study, avoidance of repeat surgery by means of $5 \mathrm{FU}$ injection confers the advantages of less scarring, reduced risk of intraoperative and post-operative complications, and all difficulties associated with harvesting more tissue from limited donor sites. Furthermore, the risk of recurrence increases with increasing number of operations. ${ }^{2}$

Maldonado $e \mathrm{al}^{26}$ studied the efficacy of a low dose of intra-operative 5FU. They concluded that this was ineffective in preventing recurrence. This is probably because of inadequate treatment both in terms of dose and duration, suggesting that a single injection is not sufficient. A single intra-operative application of MMC has been shown to be effective in reducing the recurrence of pterygium; ${ }^{9}$ however, recurrence did occur in eight of our patients. This provides the rationale for multiple post-operative use of a safe antimetabolite in recurrent cases. Our case series involved consecutive cases experiencing early recurrence of pterygium. We observed a marked reduction in vascularity and arrest of progression with repeated intra-lesional 5FU injections.

Prabhasawat $\mathrm{et} \mathrm{al}^{11}$ showed an improvement in the appearance of the local area and inhibition of progression when the lesion was injected with $5 \mathrm{mg} 5 \mathrm{FU}$ weekly for 2 weeks. Further, our results also show thinning and reduced fleshiness of the pterygium, suggesting that fibrovascular proliferation had been arrested. Ninety-three per cent of our cases experienced arrest of progression with repeated 5FU injections. This confirms the findings by Pikkel et al ${ }^{10}$ stating that $2-4$ 5FU injections $(1-3 \mathrm{mg})$ halted $83 \%$ of cases of recurrent pterygia. The novelty of our approach is in tailoring the number of injections according to clinical need. Having a pre-determined protocol for the number of injections used may disadvantage some patients, who we have shown can benefit from more injections-for example, 5 and 8 injections in two patients in this study and 
14 injections in a previously reported case. ${ }^{11}$ We believe that it is of paramount importance to use 5FU early after detection of recurrence. In our case series, treatment was started an average 7.5 days after detection of recurrence (range 0-26 days). Despite the more aggressive nature of recurrence described following excision of recurrent pterygia (secondary pterygium), the number of injections required did not appear to be related to recurrence after primary or secondary pterygia.

All three patients who experienced recurrence after excision of the secondary pterygium required only two or three injections, whereas the two patients who required five or more injections had undergone only excision of the primary pterygia. Generally, most patients required a maximum of three injections to achieve the desired clinical result.

There is considerable experience on the use of 5FU in filtering glaucoma surgery. Although adverse effects have been noted with its use, it is generally regarded as being relatively safe for subconjunctival injections. $5 \mathrm{FU}$ keratopathy, as a result of inhibition of mitosis of corneal epithelial cells, is a reported complication. ${ }^{27}$ In our case series, no epithelial toxicity was noted. We did not see any evidence of scleral thinning or infection. Our study thus demonstrates the safety of the increased number of injections when administered in the dose and manner described. We feel that the crucial aspect of scleral complications associated with antimetabolites is the presence or absence of a conjunctival cover over the treated area. When antimetabolites are applied to bare sclera the risk is greatest. In one study in which 5FU was applied to bare sclera, the risk of formation of scleral granuloma was noted to be high. ${ }^{25}$ A study that compared the histotoxic effect of MMC with that of $5 \mathrm{FU}$ found the latter to be safer in rabbit eyes. ${ }^{28}$

In glaucoma filtering surgery, 5FU application is always associated with the conjunctival cover of the area treated or injected subconjunctivally. This practice has been in vogue since $1986 .^{29}$ The maximum dosage was 3-5 mg per day, daily for 2 weeks, by subconjunctival injection, amounting to a cumulative maximum dose of $105 \mathrm{mg} .{ }^{29}$ In these studies too there was a very low incidence of corneal epitheliopathy. Our adverse events were related to the injection rather than to the drug and included a stinging sensation, despite topical

anaesthesia, and subconjunctival haemorrhage. The latter resolved in a couple of weeks in all cases.

This being a retrospective study did not have the benefit of a control population of patients who were not treated with $5 \mathrm{FU}$ or who were sham treated. This is a point that could be addressed in a future prospective study. Nevertheless, we conclude that multiple weekly injections can be safely and effectively used in the management of recurrent pterygium.
The number of injections can be titrated to clinical response and there does not seem to be a maximum upper limit. We believe that the effect would be greater if the treatment is commenced in the early stages of recurrence and hence we recommend this. In this regard, we have demonstrated in this study that 'conjunctival recurrence' is a definitive entity and suggest that clinicians should recognise conjunctival recurrence-that is, before corneal encroachment has occurred. This will prevent the fibrovascular tissue from invading on to the cornea giving a more desirable outcome and preventing further surgery.

\section{Summary}

\section{What was known before}

- Recurrence is the most common complication arising from pterygium surgery.

- In ophthalmology, 5FU is widely used owing to its antiscarring properties.

- An effective role for $5 \mathrm{FU}$ in treating recurrent pterygium was proposed in previous studies.

What this study adds

- Weekly intra-lesional 5FU injections are effective in limiting progression and inducing regression of recurrent pterygium.

- The number of injections can be tailored according to clinical need.

- Weekly administration of intra-lesional 5FU injections for the treatment of recurrent pterygium is safe with no significant adverse effects.

- The concept of conjunctival recurrence has been introduced and elaborated.

\section{Conflict of interest}

The authors declare no conflict of interest.

\section{References}

1 Kenyon KR, Wagoner MD, Hettinger ME. Conjunctival autograft transplantation for advanced and recurrent pterygium. Ophthalmology 1985; 92(11): 1461-1470.

2 Tan DT, Chee SP, Dear KB, Lim AS. Effect of pterygium morphology on pterygium recurrence in a controlled trial comparing conjunctival autografting with bare sclera excision. Arch ophthalmol 1997; 115(10): 1235-1240.

3 Riordan-Eva P, Kielhorn I, Ficker LA, Steele AD, Kirkness $\mathrm{CM}$. Conjunctival autografting in the surgical management of pterygium. Eye 1993; 7(Pt 5): 634-638.

4 Lawrence WH. The treatment of pterygium. Surv Ophthalmol 2003; 48(2): 145-180.

5 Rao SK, Lekha T, Sitalakshmi G, Padmanabhan P. Conjunctival autograft for pterygium surgery: how well does it prevent recurrence? Ophthalmic Surg Laser 1997; 28(10): 875-877 
6 Liang WH, Li RR, Deng XY. Comparison of the efficacy of pterygium resection combined with conjunctival autograft versus pterygium resection combined with amniotic membrane transplantation. Yan Ke Xue Bao 2012; 27(2): 102-105.

7 Fernandes M, Sangwan VS, Bansal AK, Gangopadhyay N, Sridhar MS, Garg P et al. Outcome of pterygium surgery: analysis over 14 years. Eye 2004; 19(11): 1182-1190.

8 Paris Fdos S, de Farias CC, Melo GB, Dos Santos MS, Batista JL, Gomes JA. Postoperative subconjunctival corticosteroid injection to prevent pterygium recurrence. Cornea 2008; 27(4): 406-410.

9 Lam DSC, Wong AKK, Fan DSP, Chew S, Kwok PSK. Tso MOM. Intraoperative mitomycin $C$ to prevent recurrence of pterygium after excision: A 30-month follow-up study. Ophthalmology 1998; 105(5): 901-905.

10 Pikkel J, Porges Y, Ophir A. Halting pterygium recurrence by postoperative 5-fluorouracil. Cornea 2001; 20(2): 168-171.

11 Prabhasawat $\mathrm{P}$, Tesavibul N, Leelapatranura K, Phonjan T. Efficacy of subconjunctival 5-fluorouracil and triamcinolone injection in impending recurrent pterygium. Ophthalmology 2006; 113(7): 1102-1109.

$12 \mathrm{Wu}$ PC, Kuo HK, Tai MH, Shin SJ. Topical bevacizumab eyedrops for limbal-conjunctival neovascularization in impending recurrent pterygium. Cornea 2009; 28(1): 103-104.

13 Lekhanont K, Patarakittam T, Thongphiew P, Suwanapichon O, Hanutsaha P. Randomized controlled trial of subconjunctival bevacizumab injection in impending recurrent pterygium: a pilot study. Cornea 2012; 31(2): 155-161.

14 Monteiro-Grillo I, Gaspar L, Monteiro-Grillo M, Pires F, Ribeiro da Silva JM. Postoperative irradiation of primary or recurrent pterygium: results and sequelae. Int J Radiat Oncol Biol Phys 2000; 48(3): 865-869.

15 Heimer R, Sartorelli AC. Reductions in gamma-globin mRNA levels restricted to the cytoplasm of 5-fluorouridine treated K-562 human erythroleukemia cells. Cancer Commun 1990; 2(1): 45-53.

16 Brazowski E, Eytan K, Eisenthal A. In vitro modulation of interleukin-2-mediated human peripheral mononuclear cell proliferation and antitumor cytotoxicity by 5 -fluorouracil. Anticancer Res 2007; 27(6B): 4135-4141.

17 Mallick KS, Hajek AS, Parrish 2nd, RK. Fluorouracil (5-FU) and cytarabine (ara-C) inhibition of corneal epithelial cell and conjunctival fibroblast proliferation. Arch Ophthalmol 1985; 103(9): 1398-1402.
18 Khaw PT, Ward S, Porter A, Grierson I, Hitchings RA, Rice NS. The long-term effects of 5-fluorouracil and sodium butyrate on human Tenon's fibroblasts. Invest Ophthalmol Vis Sci 1992; 33(6): 2043-2052.

19 Pherwani A, Vakil V, Eatamadi H, Singh R, Dua HS. Postoperative subconjunctival 5-fluorouracil in the management of recurring pterygium. Br J Ophthalmol 2007; 91(3): 398-399.

20 Coroneo MT, Di Girolamo N, Wakefield D. The pathogenesis of pterygia. Curr Opin Ophthalmol 1999; 10(4): 282-288.

21 Luanratanakorn P, Ratanapakorn T, Suwan-Apichon O, Chuck RS. Randomised controlled study of conjunctival autograft versus amniotic membrane graft in pterygium excision. Br J Ophthalmol 2006; 90(12): 1476-1480.

22 Karalezli A, Kucukerdonmez C, Akova YA, Altan-Yaycioglu $\mathrm{R}$, Borazan M. Fibrin glue versus sutures for conjunctival autografting in pterygium surgery: a prospective comparative study. Br J Ophthalmol 2008; 92(9): 1206-1210.

23 Pan H-W, Zhong J-X, Jing C-X. Comparison of fibrin glue versus suture for conjunctival autografting in pterygium surgery: a meta-analysis. Ophthalmology 2011; 118(6): 1049-1054.

24 Kandavel R, Kang JJ, Memarzadeh F, Chuck RS. Comparison of pterygium recurrence rates in Hispanic and White patients after primary excision and conjunctival autograft. Cornea 2010; 29(2): 141-145.

25 Bekibele CO, Baiyeroju AM, Olusanya BA, Ashaye AO, Oluleye TS. Pterygium treatment using 5-FU as adjuvant treatment compared to conjunctiva autograft. Eye 2006; 22(1): 31-34.

26 Maldonado MJ, Cano-Parra J, Navea-Tejerina A, Cisneros AL, Vila E, Menezo JL. Inefficacy of low-dose intraoperative fluorouracil in the treatment of primary pterygium. Arch Ophthalmol 1995; 113(11): 1356-1357.

27 Wong TT, Khaw PT, Aung T, Foster PJ, Htoon HM, Oen FTS et al. The Singapore 5-Fluorouracil Trabeculectomy Study: effects on intraocular pressure control and disease progression at 3 years. Ophthalmology 2009; 116(2): 175-184.

28 Morrow GL, Stein RM, Heathcote JG, Ikeda-Douglas JV, Feldman F. Ocular toxicity of mitomycin C and 5-fluorouracil in the rabbit. Can J Ophthalmol 1994; 29(6): 268-273.

29 Abraham LM, Selva D, Casson R, Leibovitch I. The clinical applications of fluorouracil in ophthalmic practice. Drugs 2007; 67(2): 237-255. 